\title{
Research on the Maintenance and Management Mode of High-speed Railway Infrastructure in China
}

\author{
Zhang Kexin, Zhao Zeqian, Wang Xiaotie, Xu Ning \\ Integrated Technology Research Department, China Academy of Railway Sciences, Beijing, China \\ Email address: \\ 18618142082@163.com (Zhang Kexin),18640090795@163.com (Zhao Zeqian), xtwang@rails.cn (Wang Xiaotie), \\ paulx2728@163.com (Xu Ning)
}

\section{To cite this article:}

Zhang Kexin, Zhao Zeqian, Wang Xiaotie, Xu Ning. Research on the Maintenance and Management Mode of High-speed Railway Infrastructure in China. International Journal of Transportation Engineering and Technology. Vol. 6, No. 3, 2020, pp. $102-110$. doi: $10.11648 /$ j.ijtet.20200603.15

Received: August 14, 2020; Accepted: October 12, 2020; Published: October 17, 2020

\begin{abstract}
China has preliminarily built a modern high-speed railway network, and the huge scale of the network has put forward higher requirements on infrastructure maintenance and management. In order to achieve high quality and efficient development of high-speed railway, this paper conducts research on the maintenance and management model of China's high-speed railway infrastructure. This article describes the characteristics of infrastructure maintenance management in developed countries of high-speed railways such as Japan, France and Germany; summarizes the technical characteristics of China's high-speed railways and analyzes the factors influencing infrastructure maintenance management in China. Based on the theory of organizational structure, the article systematically analyzes the differences in the work content, work methods, and means of high-speed railway infrastructure inspection and monitoring, routine maintenance, and specialized repair operations, so as to put forward the maintenance management mode of the separation of "inspection, maintenance, repair". This model mixes together the specialization of technical management and the comprehensive integration of production organization. On this basis, a comprehensive maintenance system for high-speed railway infrastructure was designed and a comprehensive maintenance organizational structure and working mechanism was proposed. Practice has shown that a comprehensive maintenance system for high-speed railway infrastructure is conducive to improving emergency response capabilities, reducing operating costs and achieving optimal resource allocation.
\end{abstract}

Keywords: High-speed Railway, Infrastructure, Maintenance Management, Comprehensive Maintenance

\section{Introduction}

The development of China High-speed Railway has shifted from speed-scale type to quality-benefit type. The "hard power" such as modern equipment and quantity of infrastructure, etc has achieved rapid growth and overall upgrading. Technological progress has brought historic and revolutionary changes in the means of front production line inspection and maintenance, and the methods of inspection, monitoring and equipment maintenance have been gradually modernized and intelligent, with a historic breakthrough made in transportation productivity.

For the traffic density of trains on high-speed railway at the same time, the sudden breakdown has a great impact with the high transmission speed in society. Therefore, the higher demands for the infrastructure malfunction safety guarantee and emergency handling ability were brought up. The current method and system of railway maintenance cannot meet the demand of the high-speed railway development. Building a new comprehensive maintenance management system for high-speed railway infrastructure is extremely urgent.

\section{Current Status of Maintenance Management of High-speed Railway Infrastructure Abroad}

\subsection{Japan}

Taking JR East Japan Railway Company as an example, its maintenance management organization implements three-level vertical management, and sets up Railway Operation Headquarters, Facility Department, Local Branch Office (Electrical Department) professional department and 
local professional technical centers (maintenance centers along the line) from top to bottom.

JR East Japan Railway Company's Shinkansen conducts maintenance system of strict separation for the "management, inspection, and maintenance". [1] The civil engineering maintenance, S\&C maintenance and power supply depot of Shinkansen is under the management of different sectors. However, due to the overall consideration of operation vehicles, operator scheduling and safety protection, the maintenance of Shinkansen has gradually evolved from specialized maintenance to multi-specialty and coordinated operation with unified planning, scheduling and command of the integrated dispatching system, and comprehensive maintenance bases were set up. The railway company is mainly responsible for the corresponding management work. The inspection and maintenance work is entrusted to the inspection and maintenance company of the outsourcing, while the outsourcing companies and the railway company only have the client-contractor relationship. [2] The efficiency, safety and convenience brought by comprehensive maintenance are fully reflected in the Shinkansen Japan.

\subsection{France}

The maintenance and repair of French railways is managed by the General Administration, regional bureaus and font-line units. The Operation Foundation Department set up under the General Administration is responsible for the maintenance and repair management of high-speed railway and existing railway. The regional bureau is in charge of the management of the subordinate comprehensive maintenance sector. A comprehensive maintenance sector is set up at the front-line unit. In addition to the general management department, two production units are built, namely the railway line work area and the S\&C electric work area.

The maintenance and repair of French high-speed railway includes regular maintenance, temporary repair and comprehensive maintenance. The mode of separation of management, inspection and repair is adopted, which is undertaken by comprehensive maintenance sector and other professional enterprises respectively. Regular maintenance and temporary repair work is carried out by the comprehensive maintenance sector under the district bureau, while large-scale maintenance work is entrusted to the line maintenance company, which conduct the maintenance work according to the signed agreement.

\subsection{Germany}

After the railway reform, Germany implemented the separation of the railway network and operation, and Deutsche Bahn kept the division system. Its organizational structure is characterized by being divided into independent subsidiary companies or departments according to different businesses, among which DB Netz is the subsidiary of Deutsche Bahn responsible for maintenance and repair of the rail network.

The internal implementation of DB Netz is the separation system of "management, inspection and repair". The so-called separation of management, inspection and repair refers to the separation of property rights management, inspection and maintenance, and repair operation. Among them, the network equipment management department is in charge of management, playing the role of "project owner"; network maintenance department is responsible for inspection, maintenance and repair; network repair department is responsible for specific repair work, which continues to entrust $85 \%$ of the workload to the outsourcing maintenance companies. [3]

To sum up, in terms of maintenance system, high-speed railways in developed countries have adopted moderate separation of "management, inspection and maintenance", and actively promote outsourcing maintenance mode. In the aspect of maintenance mode, it generally develops towards the direction of centralized maintenance, comprehensive maintenance and professional coordinated operation.

\section{Operation Characteristics and Maintenance Requirements of China High-speed Railway}

\subsection{Operation Characteristics of China High-speed Railway}

Compared with other major powers, China has built the most up-to-date railway network and the most developed high-speed railway network in the world. In terms of operation and management, the safety, comfort and punctuality of China High-speed Railway train operation has reached the world's leading position. It is the country with the largest scale and the highest operating speed of high-speed railway in the world, as well as the country with the most complex operation scenarios and external environment. The utilization rate of transport capacity is very high when trains of different speed levels operate on the dedicated lines or cross-lines, and many high-speed railways run at full load. The operation characteristics of China High-speed Railway are as follows:

\subsubsection{The Large Scale of the Rail Network, the Complex Geographical Environment and Climate Conditions}

Due to China's vast territory, the geographical environment and climate conditions of China High-speed Railway construction are highly complex [4] Adverse natural environment and climatic factors have caused equipment break down, for example lines and catenaries, which affected the normal use of railway infrastructure.

\subsubsection{Transportation Organization under the Condition of Large Traffic Volume, High Speed, High Density and High Load}

In 2017, China High-speed Railway passenger throughput was 1.75216 billion and passenger turnover was 587.56 billion passenger-km, accounting for 56.8 percent and 43.7 percent of the country's total railway passenger turnover, 
respectively. The annual passenger traffic volume of Beijing-Shanghai high-speed railway has exceeded 100 million in this year. [5]As the highest operating speed railway in the world, the highest operating speed of China High-speed Railway has reached $350 \mathrm{~km} / \mathrm{h}$. In order to meet the needs of passenger flow, a large number of dedicated line high-speed trains and cross-line high-speed trains with different speed classes are operated on China high-speed railway in densely populated areas and periods. The departure station realizes 5-minute continuous departure, and the interval of the train is tracked for $3 \mathrm{~min}$. The higher the train running speed is, the higher the requirements are for the smoothness and maintenance standards of high-speed railway.

\subsubsection{Safety, Stability and Comfort of the High-speed Train Operation}

By comparing and analyzing the safety evaluation standards at home and abroad (as shown in Table 1), the limit value of axle lateral force in the dynamic response of Chinese vehicles is evaluated at the peak value, which is more strict than the average value of UIC. [6] Moreover, China's 300 350km/h track geometry state management standard and self-developed track geometric irregularity dynamic Inspection system are the highest level in the international similar technology. Even if the speed increases from $160 \mathrm{~km} / \mathrm{h}$ to $380 \mathrm{~km} / \mathrm{h}$, the safety and stability indexes of Chinese vehicles have not changed significantly, and the riding comfort has reached the internationally recognized high standard.

Table 1. Comparison of vehicle dynamics evaluation indexes between China and UIC.

\begin{tabular}{|c|c|c|c|c|}
\hline Parameter & $\begin{array}{l}\text { Evaluation } \\
\text { Content }\end{array}$ & China Standard & UIC Standard & Comparison and Analysis \\
\hline $\begin{array}{l}\text { Derailment } \\
\text { coefficient } \\
Q / P\end{array}$ & $\begin{array}{l}\text { Evaluation of derailment } \\
\text { safety }\end{array}$ & $\left(\frac{Q}{P}\right)_{\lim }=0.8$ & {$\left[\left(\frac{Q}{P}\right)_{2 m}\right]_{\lim }=0.8$} & Equivalent to international standards \\
\hline $\begin{array}{l}\text { Wheel } \\
\text { weight } \\
\text { reduction } \\
\text { rate } \Delta P / \bar{P}\end{array}$ & $\begin{array}{l}\text { Evaluation of safety index } \\
\text { of derailment caused by } \\
\text { serious wheel load } \\
\text { reduction on one side }\end{array}$ & $\Delta \mathrm{P} / \bar{P} \leq 0.80$ & - & $\begin{array}{l}\text { UIC standard does not specify the wheel } \\
\text { load reduction rate. The test shows that when } \\
\text { the wheel weight loss rate is large, the axle } \\
\text { box generally has high frequency vertical } \\
\text { vibration of } 30 \sim 60 \mathrm{~Hz} \text {. In order to find out } \\
\text { the influence of short wave defect less than } \\
1.5 \mathrm{~m} \text { on vehicle dynamic performance, } \\
\text { dynamic wheel load reduction rate is used as } \\
\text { one of safety evaluation indexes. }\end{array}$ \\
\hline $\begin{array}{l}\text { Axle lateral } \\
\text { force } H(\mathrm{kn})\end{array}$ & $\begin{array}{l}\text { Evaluation of the } \\
\text { destructive effect of } \\
\text { vehicles on the line }\end{array}$ & $(H)_{\lim }=10+\frac{P_{0}}{3}$ & $\left(\sum H_{2 m}\right)_{\lim }=10+\frac{P_{0}}{3}$ & $\begin{array}{l}\text { According to UIC standard, the wheel axle } \\
\text { lateral force is } 2 \mathrm{~m} \text { sliding average value. In } \\
\text { the type test and joint commissioning test of } \\
\text { China, it is found that when the wheel axle } \\
\text { lateral force exceeds the limit value, it } \\
\text { generally corresponds to two kinds of line } \\
\text { defects: turnout defect and track irregularity. } \\
\text { Therefore, it is reasonable for China to } \\
\text { monitor these two kinds of line defects by } \\
\text { peak value of wheel axle lateral force. }\end{array}$ \\
\hline $\begin{array}{l}\text { Lateral } \\
\text { acceleration } \\
\text { of frame } \\
\left(\mathrm{m} / \mathrm{s}^{2}\right)\end{array}$ & $\begin{array}{l}\text { Evaluation of train lateral } \\
\text { motion stability }\end{array}$ & $\begin{array}{l}\text { After } 0.5 \sim 10 \mathrm{~Hz} \text { filtering, if } \\
\text { the peak value reaches or } \\
\text { exceeds } 8 \mathrm{~m} / \mathrm{S} 2 \text { for more } \\
\text { than } 6 \text { consecutive times } \\
\text { (including } 6 \text { times), it is } \\
\text { unqualified. }\end{array}$ & $\begin{array}{l}\text { After } 0.5 \sim 10 \mathrm{~Hz} \text { filtering, } \\
\text { if the peak value reaches or } \\
\text { exceeds } 8 \mathrm{~m} / \mathrm{S} 2 \text { for more } \\
\text { than } 6 \text { consecutive times } \\
\text { (including } 6 \text { times), it is } \\
\text { unqualified. }\end{array}$ & Equivalent to international standards \\
\hline
\end{tabular}

Notes: $Q$-Wheel lateral force; $P$ - Wheel vertical force; $\Delta P$ - Wheel load reduction; $\bar{P}$-Average wheel weight of load reduction and load increase on the side wheel; $H$-Wheel axle lateral force; $P_{0}$ - Static axle load.

\subsubsection{The Punctuality of the Train Operation}

The punctuality and high punctuality rate of trains is one of the reasons why China High-speed Railway is very popular with passengers. In order to maintain the high punctuality rate of trains, China High-speed Railway adopts a variety of technical measures to compile a highly flexible train diagram to create conditions for dispatching adjustment and maintenance. In order to avoid all kinds of defects and accidents affecting the normal operation of the trains, the thorough equipment self-diagnosis, monitoring systems and disaster prevention safety monitoring systems were established.

\subsection{Requirements for Infrastructure Maintenance}

In order to meet the operation requirements of high-speed, high-density, safe, comfortable and stable operation of the train under the conditions of large traffic volume and high load, not to disturb the regularity of train operation, ensure the high punctuality rate of the train, and provide convenient travel conditions for passengers, the maintenance work of high-speed railway infrastructure should be as follows:

\subsubsection{Safe and Reliable}

In order to ensure the high punctuality rate of trains and provide convenient travel conditions for passengers, the China high-speed railway strictly implements the Maintaining Skylight Scheme. The skylight time is generally arranged between 0:00 and 6:00. Once the maintenance window is determined on the train diagram, the skylight cannot be moved at will. [7] In view of the fact that the 
maintenance and repair of high-speed railway equipment involves a variety of factors, such as personnel, machinery, materials, external environment, and multi-professional joint operation, the relevant personnel should adhere to the safety orientation, improve the ability to predict the safety risks, achieve the prevention and control in advance, and take effective safety management and control measures.

\subsubsection{Specialization of Maintenance Technology}

High speed needs to be supported by advanced technology and equipment, as well as high standard and top-quality maintenance. For overhaul, special repair and other maintenance work with strong planning and high technical and professional level requirements, professional management should be strengthened and professional leading role should be played. The systematicness, integrity and inheritance of professional management should be enhanced.

\subsubsection{Strengthen Professional Integration}

High-speed railway project involves many systems, which are not only closely related to each system, especially the civil engineering works, S\&C electric and power supply systems, but also have a large number of interfaces and joints Therefore, the relevant personnel should strengthen professional integration, improve the management level of the joint, reduce the number of equipment maintenance operations under the independent and separate production mode of different specialties, and improve the efficiency of resource use and work.

\subsubsection{Reduce Cost and Increase Efficiency}

In order to adapt to the characteristics of high-speed railway infrastructure's high system integration, high maintenance standards and professional coordination requirements, shared Skylight scheme maintenance system and joint operation should be carried out to improve operation efficiency. At the same time, with the expansion of the scale of China's railway network, the maintenance sector is facing the challenge of increasing maintenance expenditure and operating pressure, so it pays more and more attention to scientific maintenance and takes a variety of measures to reduce the cost of equipment maintenance.

\subsubsection{Has the Rapid Response Mechanism and the Emergency Rescue Organization Command Ability}

Due to its large running density, big impact range of sudden breakdowns and fast social propagation, high-speed railway has put forward higher requirements for the safety guarantee level and emergency response capacity to the infrastructure faults. Once the fault occurs, the maintenance areas along the line should be able to quickly deploy and rush to repair, so as to restore the normal state of the equipment and driving as soon as possible. The maintenance workshop and dispatching command shall have the mechanism and organizing and commanding ability to quickly mobilize relevant resources, deal with abnormal situations, emergency response, and rapid response of emergency rescue, so as to ensure the safety of personnel and equipment under the circumstances of climatic anomalies, emergencies, equipment failures and accidents. [8]

\subsubsection{Adopt Advanced Inspection and Monitoring Means}

China railway has basically built a multi-directional and three-dimensional inspection and monitoring system, including high-speed comprehensive inspection, comprehensive inspection, vehicle carrying, professional inspection, fixed monitoring and portable equipment. With a large amount of quality and reliable infrastructure state inspection data obtained from the monitoring system, the China railway company can timely grasp the evolution law of infrastructure and predict its change trend, discover the defects and potential safety hazards of equipment application in advance, and provide strong support for scientific maintenance and accurate maintenance.

\section{Theoretical Analyses on Maintenance Management of High-speed Railway}

\subsection{Organizational Structure Theory}

According to the theory of organizational structure, through the purposeful, systematic adjustment and innovation of the right structure, the scale of the organization, and the relationship between the organization and other organizations, it can adapt to the changes of the internal and external environment, technical characteristics and organizational tasks of the organization, and improve the effectiveness of the organization.

There are two kinds of organization structure: linear function structure and process structure. Through the establishment of functional departments and the vertical management of centralization and institutionalization, the linear function organization has strong organizational execution, which is conducive to deepening the intensity of professional management and adapting to highly professional, procedural and standardized business. Process organization is an organization structure centered on business process in order to improve the response speed and efficiency to customer demand and reduce the cost of supplying products or services to customers. The establishment of a business process-centered organizational structure, which connects vertically and horizontally, emphasizes the integrity, systematicness and cooperation of management, and is suitable for integrated, efficient, flexible and fast operations.

The infrastructure maintenance of high-speed railway should set up the organizational structure according to the different business characteristics of inspection, maintenance and repair. In the process of organizational change, it should realize the flattening of organizational structure, specialization of technical management, lean of cost control, informationalization of management, mechanization of maintenance operation and comprehensive modernization of inspection.

\subsection{Analysis on Organization Form of High-speed Railway Maintenance Management}

The maintenance and management of high-speed railway 
infrastructure is mainly divided into three business types: inspection and monitoring, daily maintenance and professional repair. The characteristics of each business type are shown in figure 1. The differences in working contents, methods and measures of inspection and monitoring, daily maintenance and professional repair are very obvious, which determines its differentiated maintenance and management mode.

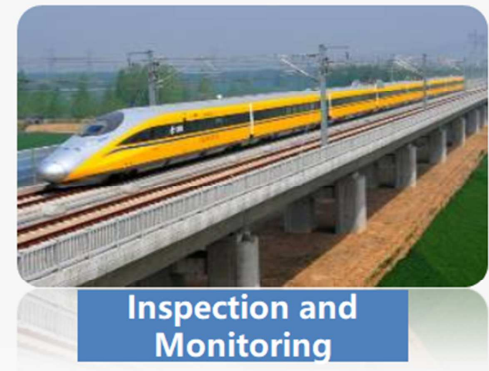

Periodic dynamic Inspection, long-term fixed-point monitoring business

Scientific inspection, comprehensive analysis and accurate evaluation

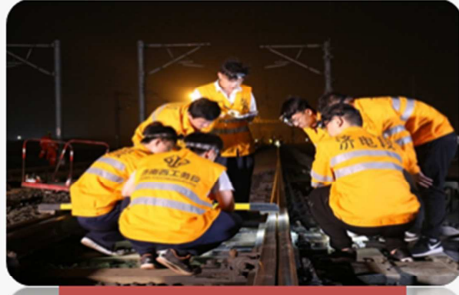

Daily Maintenance

Routine inspection and maintenance, error elimination, defect investigation and emergency treatment maintenance High frequency of work, high requirements for professional cooperation, and fast operation

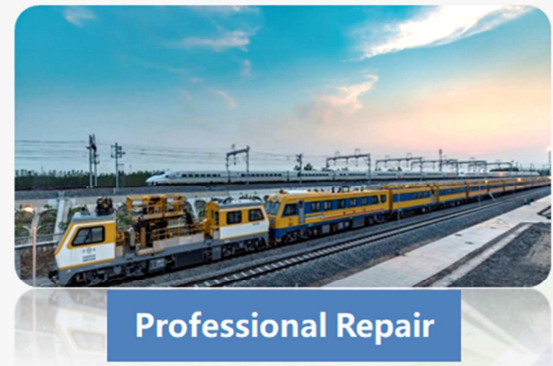

Special repair, overhaul, renovation and other planned maintenance work of each specialty Relatively fixed operation project, uniform operation process, strong planned operation, large scale and centralized efficiency

Figure 1. Different types of infrastructure maintenance management.

Inspection includes inspection and monitoring business, which requires comprehensive inspection, scientific analysis, advanced research and judgment, and accurate evaluation. It has the characteristics of timeliness, comprehensiveness and accuracy, and is suitable for the use of linear function organization form. [9] Maintenance includes daily inspection and maintenance, error elimination, defect investigation and emergency treatment, etc., requiring inspections in place, meticulous maintenance, and rapid emergency response, comprehensive, refined, rapid, and suitable for process-oriented organization [3]. Maintenance includes special repairs, overhauls, renovations, etc. of various specialties, requiring differentiated repairs, professional repairs, centralized organization, and mechanized operations. It has the characteristics of precise, professional, in-depth and efficient, and large-scale. It is suitable for linear function organization. The analysis of maintenance management organization is shown in Figure 2.

Connotation: comprehensive inspection, scientific analysis, advance research and judgment, accurate evaluation Measures: Al and informatization Features: timeliness, comprehensiveness, accuracy Applicable Model: linear function organization

Clear interface of responsibilities and rights of all parties

Conducive to the formation of scale and improvement of professional capabilities Improve inspection and maintenance quality and reduce maintenance costs
Connotation: inspection in place, meticulous maintenance, rapid emergency

Measures: integration and refinement Features: comprehensive, refined, rapid Applicable Model: process organization

Connotation: differentiated maintenance, professional maintenance, centralized organization, mechanized operation

Measures: mechanization, automation Features: accurate and professional, indepth and efficient, large scale

\section{Applicable Model: linear function organization}

Figure 2. Analysis of the organization form of infrastructure maintenance and management.

Based on the analysis of China high-speed railway infrastructure maintenance and management business types, combined with the analysis and evaluation of organizational management theory, China high-speed railway infrastructure should adopt a maintenance management plan that separates "inspection, maintenance, and repair". Inspection needs to coordinate inspection resources from China high-speed railway, establish a scientific inspection and monitoring system, and provide scientific basis and data support for maintenance. [10] Maintenance needs to give full play to the comprehensive advantages. The daily maintenance and repair implement the integration of various specialties, coordinate 
the allocation of resources, and improve the quality and efficiency. The integrated management mode of comprehensive maintenance and production should be adopted. Maintenance needs professional team, centralized organization, mechanized operation, strengthen professional management, expand the scale of maintenance, and improve quality and efficiency, it is appropriate to adopt the sub professional management mode. Under the separation mode of "inspection, maintenance and repair", different sectors are responsible for the inspection, maintenance and repair of high-speed railway infrastructure. The responsibilities, rights and interests of each sector are very clear. It effectively integrates the specialization of technical management with the comprehensive integration of production organization, so as to achieve the goal of scientific maintenance, cost reduction and efficiency improvement, and enhance the quality and efficiency of maintenance management. [11]

\section{Comprehensive Maintenance System of China High-speed Railway Infrastructure}

\subsection{Organizational Structure for Maintenance and Management of High-speed Railway Infrastructure}

Taking full account of China's national conditions, railway conditions and operation characteristics of high-speed railway, making effective use of resources outside the railway system and with the help of technical strength within the railway system, it is suggested that the comprehensive maintenance management system of China High-speed Railway infrastructure should be constructed according to the integration of internal organizational structure and the separation of "inspection, maintenance and repair" of operation organization, as shown in Figure 3.

\section{China Railway Corporation}

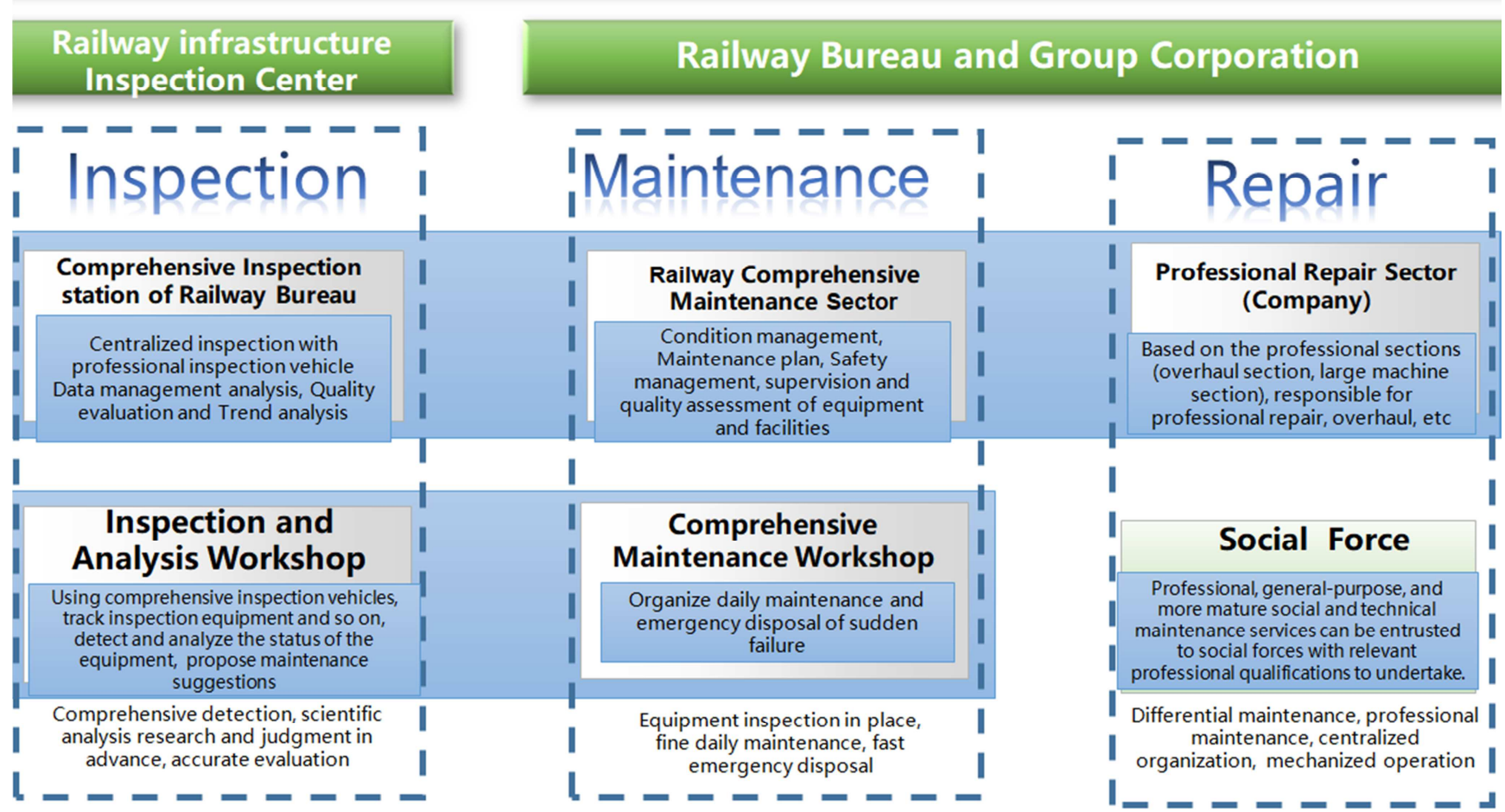

Figure 3. Construction diagram of integrated maintenance management system.

The high-speed railway infrastructure inspection system is responsible for the inspection of high-speed railway technical indicators. The information system of automatic acquisition and automatic transmission is applied, and the comprehensive maintenance train and professional inspection vehicle are used to replace the previous large number of manual detection to achieve regular inspection.

The main tasks of high-speed railway infrastructure maintenance are the daily maintenance of equipment, technical management, temporary fault treatment, and temporary repair. As the high-speed railway reserves skylight-scheme for operation at the fixed time, the maintenance of high-speed railway infrastructure avoids the uncertain factors of safety caused by the use of train interval operation on existing lines, which is conducive to the standardization of maintenance workflow.

The repair of high-speed railway infrastructure is mainly responsible for large and medium maintenance of equipment and other large-scale planned maintenance work. The use of mechanized operation methods and standardized operating procedures is conducive to strengthening professional management and expanding the scale of maintenance. At the same time, it actively introduces qualified social forces to participate, responsible for special repairs, renewal and 
equipment overhauls, etc., to achieve professional maintenance, differentiated repairs, centralized organization, and mechanized operations. [12]

\subsection{Comprehensive Maintenance Work Mechanism of High-speed Railway Infrastructure}

In order to achieve rapid response, improve the overall efficiency of equipment, reduce costs and increase efficiency, etc., it is recommended to develop a comprehensive high-speed railway maintenance work mechanism according to the requirements of "flat organizational structure, professional technical management, lean cost control, and information management methods". [13] A two-level and three-tier management structure is adopted, as shown in Figure 4. The comprehensive maintenance sector and its functional organizations are the decision-making layer, the comprehensive maintenance workshop and the special repair workshop are the organization layer, and the comprehensive maintenance area and the special repair area are the executive layer.

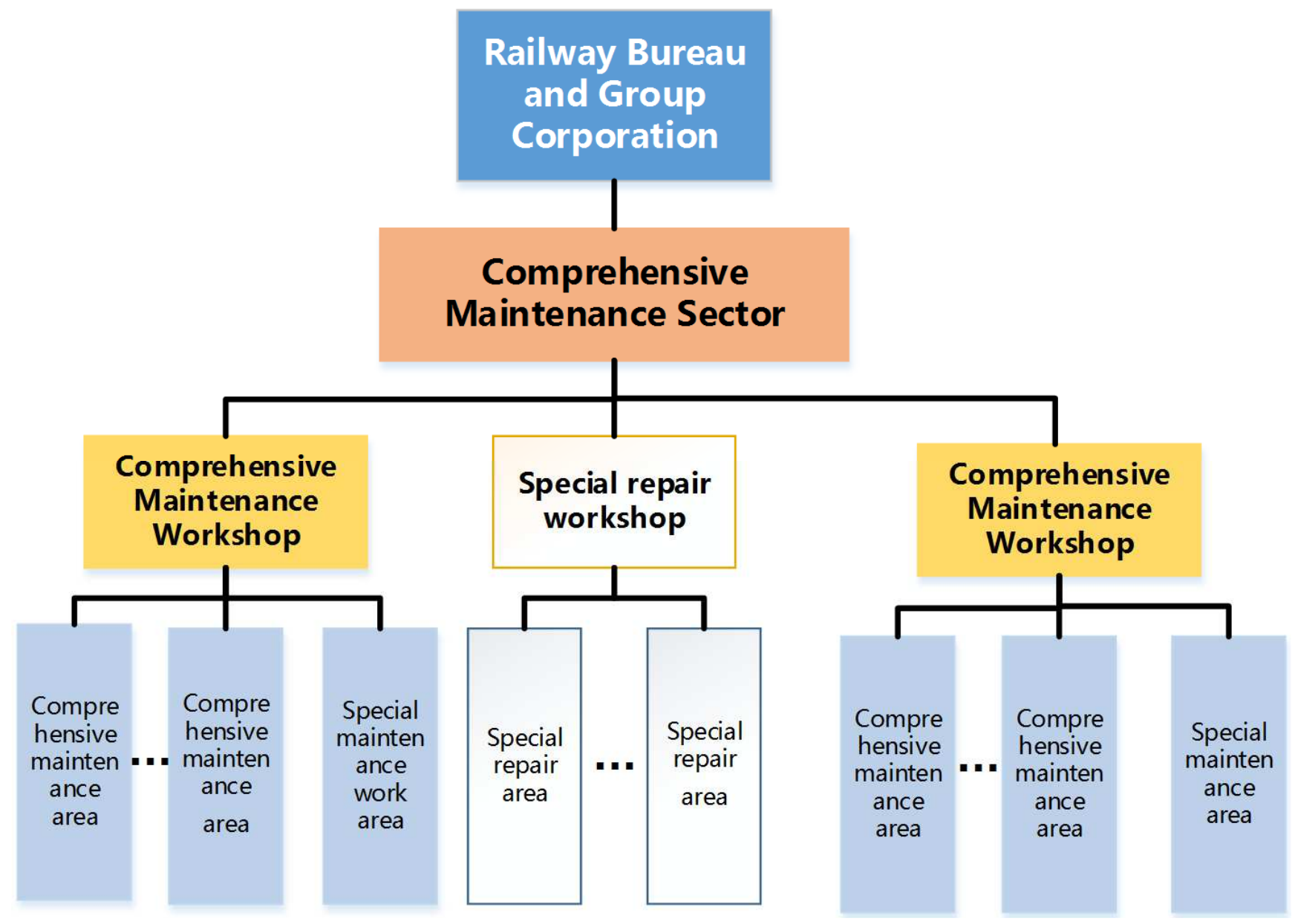

Figure 4. The comprehensive maintenance organization structure.

The key to the comprehensive maintenance of high-speed railway is the organization of production in the workshop, which moves the functions of analysis, planning, inspection, and acceptance to the workshop and the maintenance work area is responsible for on-site operations to achieve complete separation of maintenance, repair and inspection. At the same time, emergency response of the workshop as the main body is conducive to the collection of monitoring and detection information of various specialties, comprehensive analysis and judgment, and effective early warning. Implementing a joint emergency response system, centralized management and unified deployment of emergency vehicles, rescue tools, emergency personnel, etc., so as to quickly respond to emergencies and dispatch immediately, thereby improving emergency response efficiency. [14]
In addition, the comprehensive utilization of skylights scheme should be strengthened, and the comprehensive utilization and maintenance of skylights should be coordinated in the same period of time and the same region. On the basis of comprehensive utilization of skylights for the civil engineering maintenance works, S\&C sector and power supply depot, the comprehensive utilization of skylights should be extended to housing construction, vehicles and other specialties in order to maximize the comprehensive utilization rate of skylights. [15] And the comprehensive maintenance workshop and the comprehensive maintenance work area can, according to the characteristics of combined specialties, set up maintenance sectors for the equipment according to the needs, minimize the joint, and set up a special maintenance work area for the combined-specialties 
areas such as railroad switch, disaster monitoring, catenary mid-point connections, electromagnetic sleeper and so on, so as to realize the special maintenance and improve the professional level. [16]

Comprehensive maintenance should be operated according to the requirements of market, advanced maintenance technology should be introduced, and technical and management personnel with "one specialty and many abilities" should be trained. The comprehensive maintenance sector which belongs to the different railway bureau and railway group companies separately has signed the comprehensive maintenance contract with each passenger dedicated line company. The passenger dedicated-line Company pays the comprehensive maintenance fee to the comprehensive maintenance sector, and as return, the sector provides fixed equipment in good technical condition to the passenger dedicated-line Company, so as to ensure the high-speed, high-density and stable operation of the train.

\section{Conclusion}

The development of China High-speed Railway has shifted from speed-scale type to quality-benefit type. The traditional maintenance mode can no longer meet the maintenance requirements of high-speed railway. Therefore, it is urgent to establish a high-speed railway infrastructure maintenance management system which adapts to advanced and reliable high-speed railway technology, professional integration and efficient emergency response, so as to improve the level of refined and intensive management.

The different characteristics of high-speed railway infrastructure maintenance and management business determine differentiated management. China High-speed Railway infrastructure should adopt a maintenance management plan that separates "inspection, maintenance, and repair" to unify technical management specialization and production organization integration, so as to meet the development requirements of high-quality and high-efficiency of China High-speed Railway.

The comprehensive maintenance of high-speed railway infrastructure is based on the establishment of a professional repair sector. It is advisable to adopt a two-level and three-tier management structure and set up as "Comprehensive Maintenance Sector-Comprehensive Maintenance Workshop-Comprehensive Maintenance Work Area". The workshop should organize production, comprehensively utilize skylight-scheme, strengthen specialty-combined management, so as to improve the safety guarantee level, maintenance quality and efficiency of high-speed railway, and promote the high-quality development of railway to meet the increasing travel demand of the Chinese people.

\section{Acknowledgements}

This paper is one of the stage results of the major project of China Academy of Railway Sciences Group Corporation
Ltd, "Technical Research on Speed Improvement System for Existing 350 km/h High-Speed Railway" (2019YJ161).

\section{References}

[1] Jia Yonggang. Discussion on the maintenance management of high-speed railway infrastructure [J]. China Railway, 2016, (16): 7-10.

[2] Hirano J, Sussman J. Outsourcing transportation infrastructure maintenance: a theoretical approach with application to JR East [J]. Massachusetts Institute of Technology, 2004.

[3] Torbjörn Stenbeck. Quantifying Effects of Incentives in a Rail Maintenance Performance-Based Contract. 2008, 134 (4): 265-272.

[4] Lu Chunfang et al. China's high-speed railways [M]. Beijing: China Railway Press, 2013. pp. 132-134.

[5] The 6th anniversary of the safe operation of the Beijing-Shanghai high-speed railway [J]. Railway Journal, 2017, 39 (07): 150.

[6] Zu Honglin, Li Gu, Zhang Zhichao, Niu Liubin. Study on the evaluation method of wheel-track vertical force in the vehicle dynamics response of high-speed rail joint commissioning test [J]. China Railway, 2019 (07): 15-21.

[7] Chen Liqiang. Research on the opening problem of high-speed railway maintenance skylight [D]. Lanzhou Jiaotong University, 2018.

[8] Yin Bingyan, Liu Weihong. The improvement of the emergency rescue mechanism of China's high-speed railway [J]. Chinese Journal of Safety Science, 2018, 28 (S2): 180-184.

[9] Yao Dong, Chen Dongsheng, Tao Kai, Yang Fei, Wang Yanguo. Discussion on the comprehensive inspection and monitoring technology of high-speed railway infrastructure [J]. Railway Standard Design, 2020, 64 (03): 42-48.

[10] Liu Weizhen, Tu Wenjing, Yang Fei, Yang Zhipeng. Research on the integrated detection and monitoring system of high-speed railway infrastructure [J]. China Railway, 2019 (03): 22-26.

[11] Wan Jian, Duan Jianguo, Lu Zhongli. Reform and practice of integrated management of comprehensive maintenance and production of high-speed railway [J]. China Railway, 2019 (03): 16-21.

[12] Mu Wenqi, Shi Guoqiang, Wang Liuying, Shi Junling. Analysis of outsourcing maintenance mode of China's railway infrastructure in the new era [J]. China Railway, 2019 (04): 28-34.

[13] Ma Liangmin, Chen Huihua, Wang Mengjun. Research on the operation mechanism of comprehensive maintenance system of high-speed railway infrastructure [J]. Journal of Railway Science and Engineering, 2017, 14 (12): 2540-2545.

[14] Wen Xiaojie. Study on the rapid response system of railway traffic accident rescue $[\mathrm{J}]$. Chinese Journal of safety science, 2019, 29 (S2): 187-194.

[15] Chen Bo. The practice of joint maintenance operation of the Skylight on the Baolan passenger dedicated line [J]. Railway Transport and Economy, 2019, 41 (04): 28-31. 
[16] Wei Shaowei, Jiang Cheng, Jiang Ziqing, Wang Zhichao, Zhang Wenda. Research on the maintenance management mode of the interface of maintenance sector, electrical sector and power supply sector of high-speed railway in China [J]. China Railway, 2019 (04): 15-20. 